\title{
Commentary Do-not-resuscitate orders, unintended consequences, and the ripple effect
}

J Claude Hemphill III

Department of Neurology, Room 4M62, San Francisco General Hospital, 1001 Potrero Avenue, San Francisco, CA 94110, USA

Corresponding author: J Claude Hemphill III, chemphill@sfgh.ucsf.edu

Published: 2 March 2007

This article is online at http://ccforum.com/content/11/2/121

(c) 2007 BioMed Central Ltd
Critical Care 2007, 11:121 (doi:10.1186/cc5687)

likely to institute them in the first place [7]. Considerable variability has also been documented in the use of DNR orders $[8,9]$, which raises the concern that variability in decision-making regarding DNR orders might reflect larger variability in aggressiveness of care that could influence patient outcome irrespective of code status. We sought to begin to address this question using spontaneous intracerebral hemorrhage $(\mathrm{ICH})$ as a case example.

$\mathrm{ICH}$ accounts for about $15 \%$ of all stroke. With a 30-day mortality rate of about $40 \%$ and only about $20 \%$ of survivors independent at a year, $\mathrm{ICH}$ prognosis is often poor although prognosis is dependent on a variety of factors such as the Glasgow Coma Scale score on admission, hemorrhage location and size, concurrent intraventricular hemorrhage and hydrocephalus, and patient age $[10,11]$. As of writing the present article, $\mathrm{ICH}$ is also without an approved treatment of proven benefit in reducing mortality and morbidity. This has led to great heterogeneity in $\mathrm{ICH}$ care, with approaches ranging from the very aggressive to the nihilistic [12].

We hypothesized that the rate at which a hospital uses DNR orders within the first 24 hours after ICH influences patient outcome irrespective of other hospital and patient characteristics. Early DNR orders were chosen because this means that one of the very first medical decisions made for an $\mathrm{ICH}$ patient was to limit care in some manner.

From a California-wide hospital discharge database, 8,233 $\mathrm{ICH}$ patients treated at 234 different hospitals were reviewed. Interestingly, the rate at which a hospital used DNR orders for $\mathrm{ICH}$ patients within the first 24 hours independently increased the odds of individual patient death, even after adjusting for numerous patient characteristics (age, race, gender, insurance status, medical comorbidities, mechanical ventilation as a surrogate for coma) and hospital characteristics (number of $\mathrm{ICH}$ patients treated, trauma

$\mathrm{DNR}=$ do not resuscitate; $\mathrm{ICH}=$ intracerebral hemorrhage. 
center or rural hospital, teaching hospital, rate of craniotomy for $\mathrm{ICH}$ [ [13]. Even more importantly, there was an interaction between an individual patient's DNR status and the hospital DNR rate (adjusted for case mix). This means that it not only mattered whether a patient was DNR (within 24 hours of admission), but it mattered in which hospital that patient was of DNR status. Patients with the same DNR status were treated differently in different hospitals, even accounting for other patient and hospital characteristics, and this influenced their outcome. Interestingly, the group of hospitals with the highest early DNR rate (adjusted for case mix) had lower rates of intubation and mechanical ventilation, craniotomy, ventriculostomy, and cerebral angiography for $\mathrm{ICH}$ patients. They also had shorter lengths of stay and lower total costs per patient.

What does this information tell us? Are DNR orders in some patients killing other patients? No. What this means is that there is something in the way overall care is delivered in these 'high-DNR' hospitals that is increasing the risk of death in individual patients treated at those hospitals, irrespective of code status. The early DNR rate of the hospital (case mix adjusted) is acting as a proxy for overall aggressiveness of care. Even in the absence of a proven treatment for $\mathrm{ICH}$, nihilism is ineffective.

For severe neurological disorders such as $\mathrm{ICH}$, functional outcome may be even more important than mortality. It is possible that the physicians in high-DNR hospitals are vastly superior at predicting long-term functional outcome within 24 hours of acute stroke than physicians at low-DNR hospitals, thereby sparing patients destined to have a poor functional outcome by allowing them to die during hospitalization. Doubtful. More probably, this represents an overall nihilistic approach that extends to most or perhaps all $\mathrm{ICH}$ patients within a specific institution, probably based on the fallibility of attempting to prognosticate too early and too precisely. The ripple effect of an approach that emphasizes early care limitation leads to an overall milieu of nihilism that, perhaps unexpectedly, may influence attitudes of care for patients beyond those with the DNR orders themselves.

So what are we to do? Just instituting a policy prohibiting DNR orders within 24 hours of hospital admission is not the answer. It is not the DNR orders themselves, but it is the care environment that emphasizes high use of early care limitations in patients that are critically ill. This is actually not surprising given that the same physicians and nurses instituting early DNR orders in one patient may be responsible for determining the need for aggressive care in others. Whether these findings extend to other neurological conditions such as traumatic brain injury or non-neurocritical care is not known.

As we increase our emphasis in critical care on end-of-life issues and compassionate palliative care, it is essential not to
This article is part of a thematic series on End of life decision making, edited by David Crippen.

Other articles in the series can be found online at http://ccforum.com/articles/

theme-series.asp?series=CC_END

lose sight of several important principles. Precise prognostication in individual patients remains challenging, especially early after neurological catastrophes such as $\mathrm{ICH}$. An overly nihilistic approach may influence global care, potentially leading to a ripple effect beyond an individual patient. Part of the art of critical care medicine is balancing aggressive care with realistic expectations and avoiding self-fulfilling prophecies of poor outcome. I think our work is still in progress.

\section{Competing interests}

The author declares that they have no competing interests.

\section{References}

1. Levy MM, McBride DL: End-of-life care in the intensive care unit: state of the art in 2006. Crit Care Med 2006, 34(11 Suppl):S306-S308.

2. Becker KJ, Baxter AB, Cohen WA, Bybee HM, Tirschwell DL, Newell DW, Winn HR, Longstreth WT, Jr: Withdrawal of support in intracerebral hemorrhage may lead to self-fulfilling prophecies. Neurology 2001, 56:766-772.

3. Kaufmann MA, Buchmann B, Scheidegger D, Gratzl O, Radu EW: Severe head injury: should expected outcome influence resuscitation and first-day decisions? Resuscitation 1992, 23: 199-206.

4. President's Commission for the Study of Ethical Problems in Medicine and Biomedical and Behavioral Research: Deciding to Forgo Life-sustaining Treatment. US Government Printing Office; 1983.

5. Vetsch G, Uehlinger DE, Zuercher-Zenklusen RM: DNR orders at a tertiary care hospital - are they appropriate? Swiss Med Wkly 2002, 132:190-196.

6. Shepardson LB, Youngner SJ, Speroff T, Rosenthal GE: Increased risk of death in patients with do-not-resuscitate orders. Med Care 1999, 37:727-737.

7. Beach MC, Morrison RS: The effect of do-not-resuscitate orders on physician decision-making. J Am Geriatr Soc 2002, 50:2057-2061.

8. Shepardson LB, Gordon HS, Ibrahim SA, Harper DL, Rosenthal GE: Racial variation in the use of do-not-resuscitate orders. J Gen Intern Med 1999, 14:15-20.

9. Shepardson LB, Youngner SJ, Speroff T, O'Brien RG, Smyth KA, Rosenthal GE: Variation in the use of do-not-resuscitate orders in patients with stroke. Arch Intern Med 1997, 157: 1841-1847.

10. Broderick JP, Adams HP, Jr, Barsan W, Feinberg W, Feldmann E, Grotta J, Kase C, Krieger D, Mayberg M, Tilley B, et al.: Guidelines for the management of spontaneous intracerebral hemorrhage: a statement for healthcare professionals from a special writing group of the Stroke Council, American Heart Association. Stroke 1999, 30:905-915.

11. Hemphill JC, 3rd, Bonovich DC, Besmertis L, Manley GT, Johnston SC: The ICH score: a simple, reliable grading scale for intracerebral hemorrhage. Stroke 2001, 32:891-897.

12. Gregson BA, Mendelow AD: International variations in surgical practice for spontaneous intracerebral hemorrhage. Stroke 2003, 34:2593-2597.

13. Hemphill JC, 3rd, Newman J, Zhao S, Johnston SC: Hospital usage of early do-not-resuscitate orders and outcome after intracerebral hemorrhage. Stroke 2004, 35:1130-1134. 